\title{
On the Synthesis of Ornithine Carbamoyltransferase in Biotin-deficient Saccharomyces cerevisiae
}

\author{
By B. DIXON AND A. H. ROSE \\ Department of Microbiology, The University, Newcastle-upon-Tyne
}

(Received 24, June 1963)

\begin{abstract}
SUMMARY
Synthesis of ornithine carbamoyltransferase by yeast grown in a medium containing a suboptimal concentration of biotin was less than in biotinoptimal yeast and was diminished still further when L-aspartate was included in the biotin-deficient medium, although the presence of this amino acid is known to cause restoration of nucleic acid and total protein synthesis. Addition of L-ornithine to biotin-deficient medium increased synthesis of the enzyme to a value approximately half of the maximum recorded in biotin-optimal yeast, but DL-citrulline, L-glutamate, L-proline, oleate, or cytosine and uracil and their nucleosides and nucleotides had little or no stimulatory effect on synthesis of the enzyme. L-Arginine had little effect on enzyme synthesis by biotin-optimal yeast but caused a marked decrease in synthesis of the enzyme by yeast grown in biotindeficient medium containing L-aspartate. With yeast grown in unsupplemented biotin-deficient medium, but not in this medium supplemented with aspartate + ornithine, norbiotin $\left(10^{-8} \mathrm{M}\right)$ restored synthesis of the enzyme to a level greater than the maximum recorded in biotin-optimal yeast. Homobiotin $\left(10^{-8} \mathrm{M}\right)$ had a similar though less marked effect.
\end{abstract}

\section{INTRODUCTION}

The major established metabolic role of the $\mathbf{B}$ group vitamin biotin is in the fixation and transfer of $\mathrm{CO}_{2}$ (Lynen et al. 1959; Ochoa \& Kaziro, 1961; Wakil, 1961), and many of the reported effects of biotin deficiency in micro-organisms can be interpreted in terms of an impairment of $\mathrm{CO}_{2}$ metabolism. One of the most striking results of biotin deficiency in the yeast Saccharomyces cerevisiae is a diminished synthesis of ribonucleic acid and total protein (Ahmad, Rose \& Garg, 1961). These would seem to be secondary effects of an impaired ability of the yeast to fix and transfer $\mathrm{CO}_{2}$ since, by growing the yeast in a biotin-deficient medium containing aspartate, synthesis of these major cell constituents can be partially restored (Ahmad \& Rose, 1962a). Similarly, an altered lipid metabolism in biotin-deficient micro-organisms appears to be due to some extent to the inability of the organisms to carry out the biotin-dependent carboxylation of acetyl-CoA (Wakil, 1961); this would explain the biotin-sparing action of certain fatty acids (Williams \& Fieger, 1946; Hofmann, O'Leary, Yoho \& Liu, 1959).

Biotin deficiency is also known to affect adversely the synthesis of some enzymes, including the malic enzyme (Blanchard, Korkes, Del Campillo \& Ochoa, 1950) and ornithine carbamoyltransferase (OCT; E.C. 2.1.3.3; Ravel, Grona, Humphreys \& Shive, 1959), although synthesis of other enzymes is not restricted (Ahmad \& Rose, 
$1962 b$ ). The reason for this specific requirement for biotin in the synthesis of certain enzymes has not been fully explained. Studies on the role of biotin in synthesis of the malic enzyme in various micro-organisms suggested that the vitamin probably acts indirectly through its role in the synthesis of adenine (Duerre \& Lichstein, 1961), and aspartate and related compounds (Plaut, 1961; Ables, Ravel \& Shive, 1961). These findings do not explain, however, why provision of these compounds has such a profound effect on the synthesis of this particular enzyme. This applies also to the claim by Ravel, Mollenhauer \& Shive (1961) that, during synthesis of OCT in Streptococcus lactis, biotin functions in the synthesis of a 4-carbon unit, which can either be synthesized by the bacterium through a reaction involving biotin or supplied exogenously by derivatives of aspartate or by aspartate itself. This conclusion was at variance with the results reported by Ahmad \& Rose (1962b), who found that addition of L-aspartate to biotin-deficient medium caused a diminution in the synthesis of OCT by a strain of Saccharomyces cerevisiae. The present paper reports further results on the synthesis of OCT in biotin-deficient yeast. Certain of the data included in this paper have already been reported elsewhere in abstract form (Dixon \& Rose, 1963).

\section{METHODS}

Organism. The strain of Saccharomyces cerevisiae (Fleischmann) used was obtained from the Division of Applied Biology, National Research Council of Canada, Ottawa, and was maintained on slopes of malt wort agar: $10 \%(w / v)$ spray-dried malt extract ('Muntona', Munton and Fison, Ltd., Stowmarket, Suffolk) $+2 \%$ (w/v) agar. Cultures were stored at $3^{\circ}$.

Experimental cultures. All experiments were conducted using the glucose-saltsvitamins medium ( $\mathrm{pH} \mathrm{4.5)}$ ) Rose $\&$ Nickerson (1956). This medium, which in most experiments contained either an optimal $\left(8 \cdot 0 \times 10^{-10} \mathrm{M}\right)$ or a suboptimal $\left(0 \cdot 4 \times 10^{-10} \mathrm{M}\right)$ concentration of D-biotin, was supplemented with various other compounds. Biotin-sparing substances and amino acids were incorporated into media as solutions (pH 4.5). Oleic acid was added as a solution in $95 \%(v / v)$ ethanol in water; the concentration of ethanol in media never exceeded $0 \cdot 1 \%(\mathrm{v} / \mathrm{v})$. Portions $(95 \mathrm{ml}$.) of medium were dispensed into $350 \mathrm{ml}$. conical flasks which were then sterilized by autoclaving momentarily at $115^{\circ}$. Flasks were inoculated with $5 \mathrm{ml}$. of a suspension containing $1.0 \mathrm{mg}$. dry weight equivalent of washed biotin-deficient yeast per $\mathrm{ml}$. $\mathrm{M} / 15 \mathrm{KH}_{2} \mathrm{PO}_{4}$; these organisms were harvested from $120 \mathrm{hr}$ cultures of the yeast grown in biotin-deficient medium. Experimental cultures were incubated statically at $25^{\circ}$. Yeast was harvested from these cultures by centrifuging in a refrigerated $\left(0^{\circ}\right)$ centrifuge and was washed three times at $0^{\circ}$ with $\mathrm{M} / 15 \mathrm{KH}_{2} \mathrm{PO}_{4}$ before being analysed. Growth was measured turbidimetrically as described by Rose (1960), extinction readings being related to $\mathrm{mg}$. dry weight per ml. by a calibration curve.

Assays of OCT activity. Cell-free extracts of yeast were prepared as described by Ahmad \& Rose (1962b) using a Mickle tissue disintegrator (Mickle, 1948). The protein contents of the extracts were determined by the method of Lowry, Rosebrough, Farr \& Randall (1951), using crystalline bovine plasma albumin as a standard. OCT activity in cell-free extracts was determined by the method of Estes, Ravel \& Shive (1956) and the citrulline formed was estimated by the method of 
Archibald (1944). There was no detectable effect on the OCT activity of cell-free extracts when biotin $\left(16.0 \times 10^{-10} \mathrm{M}\right)$, norbiotin $\left(2.0 \times 10^{-8} \mathrm{M}\right)$ or homobiotin $(2.0 \times$ $10^{-8} \mathrm{M}$ ) was included in the reaction mixture. One unit of OCT activity was taken as the number of $\mu$ moles ornithine converted $/ \mathrm{mg}$. extract protein $/ \mathrm{hr}$ at $30^{\circ}$.

Analytical methods. Water-soluble ninhydrin-positive substances were extracted from the yeast by suspending the equivalent of $10 \mathrm{mg}$. dry weight of washed organisms in $10 \mathrm{ml}$. water and placing the suspension in a boiling water bath for 15 min. On cooling, the supernatant fluid was removed from the cell debris by centrifugation and, after being supplemented by washings $(2.0 \mathrm{ml}$.) from the debris, the volume of extract was made up to $10 \mathrm{ml}$. with water. Total ninhydrin-positive substances in these extracts were estimated by a modification of the method of Smith \& Agiza (1951) described by Hagen \& Rose (1962), using glycine as a standard. Results are expressed as $\mu \mathrm{g}$. $\mathrm{NH}_{2} / 10 \mathrm{mg}$. dry weight yeast. The ornithine content of water extracts of the yeast was determined by the method of Chinard (1952) and the arginine content by the method of Rosenberg, Ennor \& Morrison (1956).

The contents of acid-soluble ultraviolet (u.v.)-absorbing substances and RNA in the yeast were determined spectrophotometrically using the procedure described by Ahmad et al. (1961). Protein in the residue remaining after nucleic acids and related substances had been extracted from the yeast was determined by the micro-Kjeldahl method (Markham, 1942) using a mercuric oxide catalyst (Miller \& Houghton, 1945).

Chemicals. All compounds used in this study were screened for possible contamination with biotin by examining the ability of the compound to stimulate growth of the biotin-requiring yeast in biotin-free basal medium (Ahmad \& Rose, 1962a); contaminated compounds were washed or recrystallized until shown to be free of biotin. Amino acids were examined chromatographically for purity and, with the exception of citrulline which contained a trace of ornithine, all were found to be free of contaminating ninhydrin-positive compounds. The sample of oleic acid used was shown by gas chromatography to contain $76 \%(\mathrm{w} / \mathrm{w})$ oleic acid, the principal contaminant being elaidic acid $(22 \% \mathrm{w} / \mathrm{w})$, the trans isomer of oleic acid. Asparagine, citrulline and oleic acid were obtained from British Drug Houses Ltd, Poole, Dorset. All other amino acids, together with vitamins, carbamoyl phosphate, cytosine and uracil were purchased from L. Light and Co. Ltd, Colnbrook, Buckinghamshire, and nucleosides and nucleotides from C.P. Boehringer und Soehne, G.m.b.H., Mannheim, West Germany.

\section{RESULTS}

\section{Growth and synthesis of ornithine carbamoyltransferase under conditions of biotin deficiency}

Growth of the yeast in biotin-optimal medium and in supplemented and unsupplemented biotin-deficient media is shown in Fig. 1; OCT activities of extracts of yeast grown in each of these media are given in Fig. 2.

In yeast grown in biotin-optimal medium, enzyme synthesis increased rapidly during the early part of the exponential phase of growth, but thereafter declined. Growth of, and OCT synthesis by, the yeast were severely restricted in unsupplemented biotin-deficient medium. Supplementing the biotin-deficient medium with 
L-aspartate caused an initial stimulation of growth but led to a further diminution of OCT synthesis. In oleate-supplemented biotin-deficient medium, there was a much slower stimulation of growth and OCT synthesis was slightly higher than in yeast grown in unsupplemented biotin-deficient medium. When the yeast was grown in biotin-deficient medium supplemented with aspartate +oleate, there was a stimulation of growth which, especially in the early stage of growth, was slightly greater than the sum of the stimulations caused by aspartate and oleate singly. OCT synthesis in yeast grown in this medium was greater than that in yeast grown in biotin-deficient medium supplemented with only aspartate, but was still below the maximum reached in yeast grown in unsupplemented biotin-deficient medium.

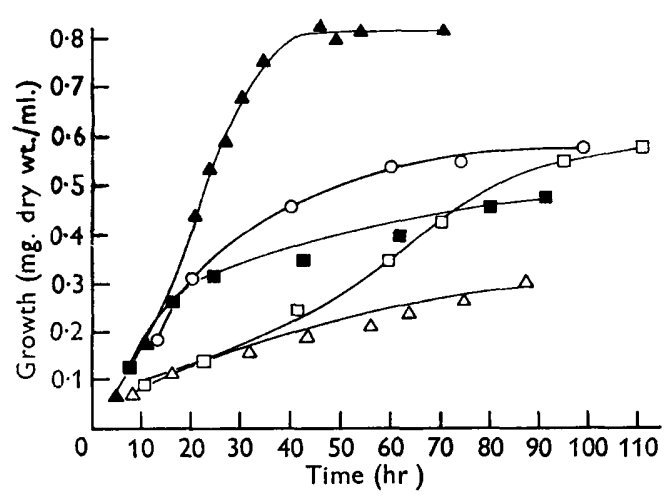

Fig. 1

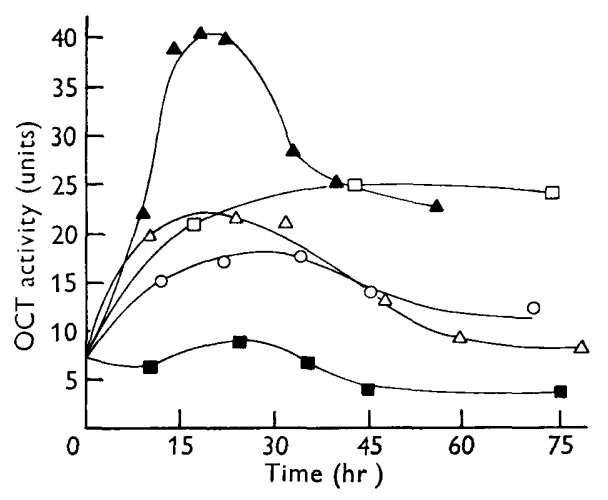

Fig. 2

Figs. 1 and 2. Growth of (Fig. 1) and ornithine carbamoyltransferase activity in extracts of (Fig. 2) yeast grown in media containing an optimal concentration $\left(8.0 \times 10^{-10} \mathrm{M} ; \Delta\right)$ of biotin or a suboptimal concentration $\left(0 \cdot 4 \times 10^{-10} \mathrm{M}\right)$ either unsupplemented $(\triangle)$ or supplemented with $\mathrm{L}$-aspartate $\left(2 \cdot 0 \times 10^{-3} \mathrm{M} ; \boldsymbol{m}\right)$, oleate $(100 \mu \mathrm{g} . / \mathrm{ml}$; $\square)$ or aspartate + oleate (O).

The effects of these conditions of biotin deficiency on growth of, and OCT synthesis by, the yeast were therefore similar to those reported in brief by Ahmad \& Rose $(1962 b)$ although these workers used a much smaller inoculum. Yeast grown under the conditions employed in the present study also showed changes in the contents of acid-soluble u.v.-absorbing substances, RNA and intracellular amino acids similar to those reported by Ahmad \& Rose $(1962 a, b)$.

\section{Effect of potential inducer and repressor compounds on ornithine carbamoyltransferase synthesis}

In order to examine the possible effects of biotin deficiency on feed-back mechanisms controlling the synthesis of OCT, a study was made of the effect of incorporating potential inducer and repressor compounds in the medium. Compounds tested included L-proline, L-arginine and intermediates on the biosynthetic pathway to arginine in yeast, namely L-glutamate, L-ornithine and DL-citrulline (Abelson \& Vogel, 1955; Scher \& Vogel, 1957). Incorporation of citrulline, glutamate or proline in concentrations up to $500 \mu \mathrm{g} . / \mathrm{ml}$. in biotin-optimal medium or in unsupplemented or aspartate-supplemented biotin-deficient medium had no detectable 
effect on growth or OCT synthesis as compared with yeast grown in media lacking these amino acids. Ornithine, however, caused a modest stimulation of enzyme synthesis (Table 1). In yeast grown in biotin-optimal or in biotin-deficient medium containing $100 \mu \mathrm{g}$. ornithine $/ \mathrm{ml}$, there was an increase of up to $60 \%$ in the synthesis of OCT as compared with yeast grown in the corresponding medium lacking ornithine. OCT synthesis was considerably diminished in yeast grown in aspartatesupplemented biotin-deficient medium as compared with yeast grown in unsupplemented biotin-deficient medium (Fig. 2), but addition of ornithine to the aspartatesupplemented biotin-deficient medium caused an approximately fourfold increase in specific activity. A similar though less marked effect was found using media containing L-asparagine instead of L-aspartate. Addition of ornithine, at the same concentration, to oleate-supplemented biotin-deficient medium caused little or no change in OCT synthesis in the yeast but, when added to biotin-deficient medium containing oleate + aspartate, an increase in specific activity of up to $60 \%$ was recorded.

Table 1. Effect of L-ornithine on ornithine carbamoyltransferase synthesis in biotin-optimal and biotin-deficient yeast

\begin{abstract}
Yeast was grown in a biotin-deficient medium with and without the supplements indicated below. After harvesting, the yeast was washed, disintegrated, and the OCT activities of the cell-free extracts determined as described in Methods. Ornithine was included in media at $100 \mu \mathrm{g} . / \mathrm{ml}$.
\end{abstract}

\begin{tabular}{|c|c|c|c|}
\hline \multirow[b]{2}{*}{$\begin{array}{l}\text { Supplements in } \\
\text { biotin-deficient medium }\end{array}$} & \multirow[b]{2}{*}{$\begin{array}{l}\text { Age of } \\
\text { culture } \\
\text { (hr) }\end{array}$} & \multicolumn{2}{|c|}{ OCT activity (units) } \\
\hline & & $\begin{array}{l}\text { Medium } \\
\text { lacking } \\
\text { ornithine }\end{array}$ & $\begin{array}{l}\text { Medium } \\
\text { containing } \\
\text { ornithine }\end{array}$ \\
\hline None & $\begin{array}{l}17 \\
27 \\
41\end{array}$ & $\begin{array}{l}20 \cdot 5 \\
19 \cdot 3 \\
18 \cdot 2\end{array}$ & $\begin{array}{l}29 \cdot 2 \\
25 \cdot 9 \\
24 \cdot 6\end{array}$ \\
\hline L-Aspartate (2.0 mM) & $\begin{array}{l}10 \\
22 \\
35\end{array}$ & $\begin{array}{l}6 \cdot 3 \\
8 \cdot 4 \\
6 \cdot 6\end{array}$ & $\begin{array}{l}25 \cdot 0 \\
22 \cdot 0 \\
19 \cdot 0\end{array}$ \\
\hline L-Asparagine (2.0 mM) & $\begin{array}{l}12 \\
19 \\
36\end{array}$ & $\begin{array}{r}7 \cdot 9 \\
10 \cdot 5 \\
8 \cdot 7\end{array}$ & $\begin{array}{l}20 \cdot 0 \\
22 \cdot 3 \\
15 \cdot 5\end{array}$ \\
\hline Oleate $(100 \mu \mathrm{g} . / \mathrm{ml})$. & $\begin{array}{l}17 \\
43 \\
75 \\
89\end{array}$ & $\begin{array}{l}21 \cdot 0 \\
25 \cdot 0 \\
24 \cdot 5 \\
20 \cdot 5\end{array}$ & $\begin{array}{l}22 \cdot 8 \\
27 \cdot 2 \\
26 \cdot 0 \\
21 \cdot 2\end{array}$ \\
\hline $\begin{array}{l}\text { L-Aspartate (2.0 mu) +oleate } \\
(100 \mu \mathrm{g} . / \mathrm{ml} .)\end{array}$ & $\begin{array}{l}12 \\
35 \\
46\end{array}$ & $\begin{array}{l}15 \cdot 3 \\
17 \cdot 5 \\
14 \cdot 3\end{array}$ & $\begin{array}{l}24 \cdot 3 \\
23 \cdot 5 \\
19 \cdot 6\end{array}$ \\
\hline Biotin (0.76 $\mathrm{m} \mu \mathrm{M}$; optimal) & $\begin{array}{l}12 \\
22 \\
35\end{array}$ & $\begin{array}{l}30 \cdot 5 \\
42 \cdot 5 \\
27 \cdot 5\end{array}$ & $\begin{array}{l}35 \cdot 2 \\
65 \cdot 5 \\
39 \cdot 5\end{array}$ \\
\hline
\end{tabular}

Increasing the concentration of ornithine in the medium to $500 \mu \mathrm{g} . / \mathrm{ml}$. (Fig. 3) had no effect on growth, while synthesis of OCT was either unaffected or diminished. At concentrations lower than $100 \mu \mathrm{g}$./ml., OCT synthesis by yeast grown in biotinoptimal medium or in unsupplemented biotin-deficient medium was diminished, but synthesis in yeast grown in aspartate-supplemented biotin-deficient medium 
increased and was at a maximum in yeast grown in media containing $50 \mu \mathrm{g}$. ornithine/ml.

When arginine $(100 \mu \mathrm{g} . / \mathrm{ml}$.) was included in biotin-optimal medium, OCT synthesis by the yeast was slightly but consistently higher than in yeast grown in arginine-free biotin-optimal medium. However, arginine at this concentration had no effect on OCT synthesis in unsupplemented biotin-deficient medium or in this medium supplemented with oleate or oleate+aspartate. In biotin-deficient

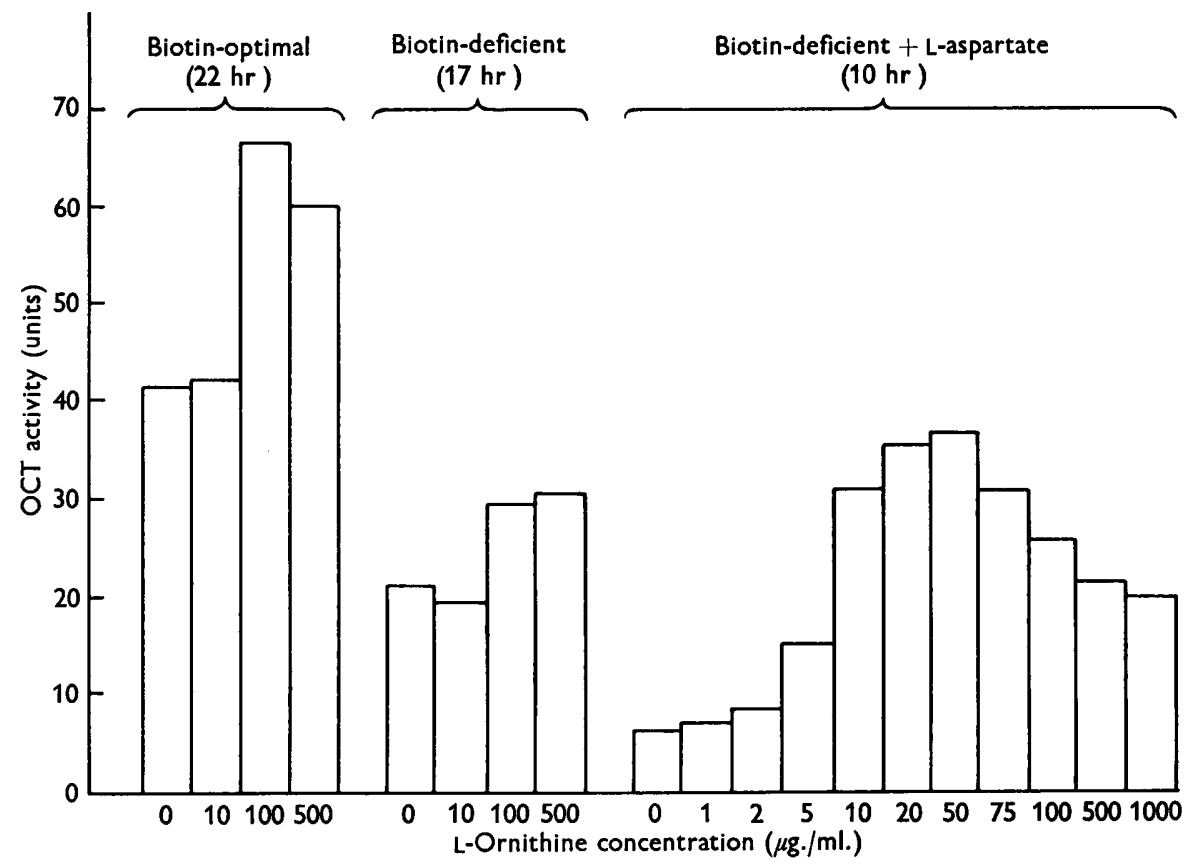

Fig. 3. Effect of L-ornithine concentration on induction of ornithine carbamoyltransferase synthesis in yeast grown in medium containing an optimal concentration $\left(8.0 \times 10^{-10} \mathrm{M}\right)$ of biotin, or a suboptimal concentration $\left(0.4 \times 10^{-10} \mathrm{M}\right)$ with and without $\mathrm{L}$-aspartate $\left(2 \cdot 0 \times 10^{-3} \mathrm{M}\right)$ together with $\mathrm{L}$-ornithine at the concentration indicated.

Table 2. Effect of L-arginine on induction of ornithine carbamoyltransferase by L-ornithine in biotin-optimal and biotin-deficient yeast

Experimental details are as described in Table 1. Arginine and ornithine were each included in media at $100 \mu \mathrm{g} . / \mathrm{ml}$., and aspartate at $2 \cdot 0 \mathrm{mM}$.

\begin{tabular}{|c|c|c|c|}
\hline \multirow[b]{2}{*}{ Medium } & \multirow[b]{2}{*}{$\begin{array}{c}\text { Age of } \\
\text { culture } \\
\text { (hr) }\end{array}$} & \multicolumn{2}{|c|}{ OCT activity (units) } \\
\hline & & $\begin{array}{c}\text { Medium } \\
\text { lacking } \\
\text { arginine }\end{array}$ & $\begin{array}{l}\text { Medium } \\
\text { containing } \\
\text { arginine }\end{array}$ \\
\hline
\end{tabular}

Biotin-optimal

Biotin-optimal + ornithine

29

rginin

Biotin-deficient

$42 \cdot 5$

$43 \cdot 5$

$62.5 \quad 66.0$

Biotin-deficient + ornithine

$\mathbf{2 0 \cdot 5}$

$\mathbf{2 0} \cdot \mathbf{0}$

$29 \cdot 2$

$28 \cdot 6$

Biotin-deficient + aspartate

Biotin-deficient + aspartate +

$6 \cdot 3$

$3 \cdot 8$ ornithine

$\mathbf{2 5} \cdot 0$

$23 \cdot 2$ 
medium supplemented with aspartate + arginine, there was a diminution in enzyme synthesis as compared with that in yeast grown in arginine-free aspartate-supplemented biotin-deficient medium. As shown in Table 2, the presence in the medium of $100 \mu \mathrm{g}$. arginine $/ \mathrm{ml}$. did not affect the ability of ornithine $(100 \mu \mathrm{g} . / \mathrm{ml}$.) to induce synthesis of OCT.

In all experiments in which ornithine or arginine was included in media, it was shown, by determinations of the concentrations of total ninhydrin-positive substances, ornithine and arginine in the intracellular pools, that these amino acids had penetrated the cell (Table 3). It was also clearly established that arginine was able to enter the yeast in the presence of exogenous ornithine.

Table 3. Arginine and ornithine contents of intracellular amino acid pools of yeast grown in biotin-optimal medium and in basal and supplemented biotin-deficient media containing different concentrations of L-arginine or L-ornithine

Yeast was grown in biotin-optimal or biotin-deficient medium supplemented as indicated in the table. After harvesting the cell crops, a suspension of the washed yeast was placed in a boiling water bath for $10 \mathrm{~min}$. to liberate intracellular amino acids. The concentrations of arginine and/or ornithine in these water extracts were then determined as described in Methods.

Supplement in biotin-deficient medium

Biotin (0.76 m $\mu \mathrm{M}$; optimal)
Age of culture (hr)

$\overbrace{\text { Ornithine }}^{\begin{array}{c}\text { Concn. in medium } \\ (\mu \mathrm{mole} / \mathrm{ml} .)\end{array}}$

L-Aspartate (2.0 $\mathrm{mm})$

Oleate (100 $\mu \mathrm{g} . / \mathrm{ml}$.
22

0
10
100
500
-
-
$\overline{100}$

17

0

10

100

500

-

100

10

0

10

100

500

100

40
Concn. in intracellular pool ( $\mu \mathrm{mole} / \mathrm{mg}$. dry wt. cells)

\begin{tabular}{|c|c|}
\hline Ornithine & Arginine \\
\hline 0.05 & - \\
\hline $0 \cdot 12$ & - \\
\hline $0 \cdot 28$ & $0 \cdot 16$ \\
\hline- & - \\
\hline- & $0 \cdot 18$ \\
\hline- & $\mathbf{0} \cdot \mathbf{3 7}$ \\
\hline- & 0.54 \\
\hline- & 0.41 \\
\hline 0.03 & - \\
\hline 0.03 & - \\
\hline 0.05 & $\mathbf{0 \cdot 3 1}$ \\
\hline $0 \cdot 14$ & - \\
\hline- & 0.25 \\
\hline - & 0.41 \\
\hline 一 & $0 \cdot 74$ \\
\hline- & 0.48 \\
\hline 0.02 & - \\
\hline 0.08 & - \\
\hline $0 \cdot 17$ & $0 \cdot 13$ \\
\hline $0 \cdot 65$ & - \\
\hline - & $0 \cdot 10$ \\
\hline - & $\mathbf{0} \cdot \mathbf{2 3}$ \\
\hline- & $0 \cdot 49$ \\
\hline- & $0 \cdot 20$ \\
\hline 0.03 & - \\
\hline 0.05 & - \\
\hline 0.07 & - \\
\hline $0 \cdot 23$ & - \\
\hline - & $0 \cdot 21$ \\
\hline - & $0 \cdot 22$ \\
\hline - & $0 \cdot 34$ \\
\hline- & $0 \cdot 88$ \\
\hline
\end{tabular}




\section{Effect of cytosine and uracil and their ribonucleosides and ribonucleotides on ornithine carbamoyltransferase synthesis}

Rogers \& Novelli (1960) reported that synthesis of OCT by lysates from protoplasts of Escherichia coli strain W was exceptional in requiring cytidine triphosphate (CTP) and uridine triphosphate (UTP) in addition to the normal requirement for guanosine triphosphate (GTP) in protein synthesis. It seemed of interest, therefore, to examine the effect of uracil and cytosine and their ribonucleosides and ribonucleotides on OCT synthesis, since the diminished synthesis of this enzyme in biotin-deficient yeast might be due to a shortage of CTP or UTP. The results of this investigation, which are given in Table 4, showed that, while addition of cytosine + uracil to biotin-deficient medium caused a slight increase in OCT specific activity in cell-free extracts, other combinations tested in both supplemented and unsupplemented biotin-deficient medium failed to stimulate synthesis of the enzyme.

Table 4. Ornithine carbamoyltransferase synthesis by yeast grown in media supplemented with cytosine, and uracil and their ribonucleosides and ribonucleotides

Experimental details are as described under Table 1. With the exception of cytidylic acid, each supplement was present at $2.0 \times 10^{-5} \mathrm{M}$; cytidylic acid, which is sparingly soluble in water, was present as a saturated solution.

\begin{tabular}{|c|c|c|c|c|c|}
\hline \multirow[b]{2}{*}{$\begin{array}{l}\text { Supplements in } \\
\text { biotin-deficient medium }\end{array}$} & \multirow[b]{2}{*}{$\begin{array}{c}\text { Age of } \\
\text { culture } \\
\text { (hr) }\end{array}$} & \multicolumn{4}{|c|}{$\begin{array}{l}\text { OCT activity (units) of extracts of yeast grown } \\
\text { in medium containing }\end{array}$} \\
\hline & & $\begin{array}{c}\text { Cytosine }+ \\
\text { uracil }\end{array}$ & $\begin{array}{l}\text { Cytidine }+ \\
\text { uridine }\end{array}$ & $\begin{array}{c}\text { Cytidylic } \\
\text { acid+ } \\
\text { uridylic } \\
\text { acid }\end{array}$ & $\begin{array}{l}\text { No } \\
\text { additions }\end{array}$ \\
\hline None & 42 & $19 \cdot 7$ & $18 \cdot 4$ & $17 \cdot 5$ & $17 \cdot 0$ \\
\hline L-Aspartate $(2.0 \mathrm{~mm})+$ oleate & 10 & $25 \cdot 8$ & $27 \cdot 6$ & $26 \cdot 2$ & $25 \cdot 8$ \\
\hline
\end{tabular}

(100 $\mu \mathrm{g} . / \mathrm{ml}$.)

Table 5. Ornithine carbamoyltransferase synthesis by yeast grown in media containing biotin homologues

\begin{tabular}{|c|c|c|c|c|}
\hline \multirow[b]{2}{*}{$\begin{array}{l}\text { Supplements in } \\
\text { biotin-deficient medium }\end{array}$} & \multirow{2}{*}{$\begin{array}{c}\text { Age of } \\
\text { culture } \\
\text { (hr) }\end{array}$} & \multicolumn{3}{|c|}{$\begin{array}{c}\text { OCT activity (units) of extracts of yeast grov } \\
\text { in medium containing }\end{array}$} \\
\hline & & $\begin{array}{l}\text { Norbiotin } \\
\left(10^{-8} \mathbf{M}\right)\end{array}$ & $\begin{array}{l}\text { Homobiotin } \\
\quad\left(10^{-8} \mathrm{M}\right)\end{array}$ & $\begin{array}{c}\text { No } \\
\text { additions }\end{array}$ \\
\hline None & $\begin{array}{l}16 \cdot 5 \\
65\end{array}$ & $\begin{array}{r}69 \cdot 6 \\
102 \cdot 0\end{array}$ & $\begin{array}{l}56 \cdot 2 \\
\mathbf{3 5} \cdot 5\end{array}$ & $\begin{array}{l}22 \cdot 2 \\
13 \cdot 2\end{array}$ \\
\hline Biotin (0.76 $\mathrm{m} \mu \mathrm{M}$; optimal) & $\begin{array}{l}18 \\
42\end{array}$ & $\begin{array}{l}\mathbf{3 7} \cdot \mathbf{5} \\
\mathbf{2 4} \cdot \mathbf{3}\end{array}$ & $\begin{array}{l}38 \cdot 5 \\
25 \cdot 9\end{array}$ & $\begin{array}{l}38 \cdot 6 \\
25 \cdot 5\end{array}$ \\
\hline $\begin{array}{l}\text { L-Aspartate (2.0 mM) + L-ornithine } \\
(100 \mu \mathrm{g} . / \mathrm{ml} .)\end{array}$ & $\begin{array}{l}10 \\
22\end{array}$ & $\begin{array}{l}24 \cdot 5 \\
21 \cdot 5\end{array}$ & $\begin{array}{l}25 \cdot 4 \\
22 \cdot 6\end{array}$ & $\begin{array}{l}\mathbf{2 6} \cdot 0 \\
\mathbf{2 2 \cdot 0}\end{array}$ \\
\hline
\end{tabular}

\section{Effect of biotin analogues on synthesis of ornithine carbamoyltransferase}

Several analogues of biotin have been reported to replace the biotin requirement of micro-organisms or to act as metabolic antagonists of the vitamin (Goldberg et al. 1947). Since it appeared that biotin was essential for maximum synthesis of OCT by the yeast even in media containing aspartate + ornithine, an examination was 
made of the ability of certain biotin analogues to replace the biotin requirement for synthesis of the enzyme. Analogues tested included biotinol, the alcohol analogue of biotin, oxybiotin in which the sulphur atom is replaced by oxygen, and norbiotin and homobiotin which contain respectively one fewer and one more $\mathrm{CH}_{2}$ group in the side chain. At concentrations of $0.5 \times 10^{-10} \mathrm{M}$ and above, both biotinol and oxybiotin stimulated growth of the yeast, but with norbiotin and homobiotin stimulation of growth was not observed until the concentration in the medium was raised to $10^{-7} \mathrm{M}$. An examination was therefore made of the effect of norbiotin and homobiotin on OCT synthesis by the yeast at a concentration $\left(10^{-8} \mathrm{M}\right)$ below that which stimulated growth. The results are given in Table 5. Norbiotin, and to a lesser extent homobiotin, caused a very marked stimulation of OCT synthesis in biotin-deficient medium. However, in biotin-optimal medium and in biotindeficient medium supplemented with aspartate + ornithine, these homologues were without effect on OCT synthesis.

\section{DISCUSSION}

Synthesis of ornithine carbamoyltransferase in the strain of Saccharomycescerevisiae used in this study is inducible by ornithine and, under certain conditions, repressible by arginine. It differs, therefore, from the strain of $S$. cerevisiae examined by Bechet, Wiame \& De Deken-Grenson (1962) in which end-product (arginine) repression of OCT synthesis was demonstrated but not induction by ornithine. Induction of OCT synthesis has, however, been previously reported by Gorini (1960) in a strain of Escherichia coli, in which ornithine was found to induce enzyme synthesis under conditions of partial arginine repression.

The diminution of OCT synthesis caused by growing the yeast in a medium containing a suboptimal concentration of biotin would seem to be due in part to an impairment in the mechanism for the induced synthesis of this enzyme. The data in this paper suggest that this is possibly caused by the presence of a lower concentration of intracellular ornithine in yeast grown in biotin-deficient medium as compared with biotin-optimal yeast, and also a decreased sensitivity of the induction mechanism in biotin-deficient yeast to the presence of exogenous ornithine. Thus induced synthesis of the enzyme in biotin-deficient yeast becomes considerably more sensitive to the presence of exogenous ornithine when the yeast is grown in biotin-deficient medium supplemented with aspartate or asparagine. This may be due to an enhanced ability on the part of the aspartate-grown biotin-deficient yeast to accumulate ornithine, but it is also conceivable that the restoration of nucleic acid and total protein synthesis caused by aspartate has led to an increased synthesis of repressor substances (? protein) (Jacob \& Monod, 1961; Chantrenne, 1963), so making the mechanism controlling enzyme synthesis more sensitive to derepression by inducer. Another possible explanation is that ornithine antagonizes a repression of OCT synthesis caused by aspartate. But repression by aspartate would not seem to be an example of end-product repression, such as that caused by arginine, since OCT is not known to catalyse reactions leading to aspartate synthesis. Moreover, aspartate does not repress OC'T synthesis in biotin-optimal yeast. It is more likely that the observed effects of aspartate on OCT synthesis in biotin-deficient yeast are the results of changes in the composition and utilization of amino acids in the intracellular pool (Table 3). The inability of oleate, when added to unsupplemented or 
aspartate-supplemented biotin-deficient medium, to affect the response of the yeast to exogenous ornithine suggests that any restoration of normal membrane structure brought about by growth in the presence of oleate (Rose, 1963) is not in itself necessary for the response of the OCT-synthesizing system to exogenous ornithine.

However, none of the combinations of biotin-sparing substances tested, in the presence or absence of ornithine, stimulated synthesis of OCT in biotin-deficient yeast to a level approaching that in biotin-optimal yeast, the greatest activity recorded being only one-half of the maximum obtained in biotin-optimal yeast. This suggests that the role of biotin in synthesis of OCT in this yeast may differ from that in Streptococcus lactis in which, according to Ravel et al. (1961), it acts by mediating synthesis of a 4-carbon compound which can be supplied exogenously by derivatives of aspartate (e.g. asparagine peptides) or less effectively by aspartate. These workers found, however, that high concentrations of aspartate or lower concentrations of asparagine raised OCT synthesis to only about half of that in the presence of optimal biotin. Furthermore, the inability of uracil and cytosine, and their ribonucleosides and ribonucleotides, to spare the biotin requirement for OCT synthesis by the yeast would seem to indicate that the restriction in synthesis of this enzyme is not caused by a deficiency of CTP or UTP which Rogers \& Novelli (1960) reported were required for OCT synthesis in extracts of Escherichia coli.

The possibility of a direct role for biotin must be considered in view of the ability of norbiotin and homobiotin to replace the biotin requirement for OCT synthesis without affecting growth. These homologues may act by replacing biotin as a coenzyme in one or more biotin-containing enzymes concerned in OCT synthesis, and the fact that growth of the yeast is not affected suggests that these homologues cannot replace biotin in certain other biotin-containing enzymes. Little, if anything, is known of the ability of these biotin homologues to replace biotin as the coenzyme in biotin-containing enzymes, so it is not possible to speculate regarding the nature of any such enzymes which may be acting in the synthesis of OCT. The finding that synthesis of the enzyme in yeast grown in biotin-deficient medium containing one of these biotin homologues was greater than in biotin-optimal yeast can be explained by assuming that the normal repression mechanisms are not operating in the biotin-deficient yeast. The reason for the inability of the homologues to stimulate OCT synthesis in yeast grown in biotin-deficient medium containing aspartate might, on the other hand, be due to an increased synthesis of repressor substances in this yeast, or possibly to the inability of these homologues to catalyse synthesis of a compound capable of antagonizing the repression by aspartate.

One might speculate, therefore, that in this strain of Saccharomyces cerevisiae, biotin functions in the synthesis of OCT partly through its role in the synthesis of inducer, ornithine, partly through its role in the synthesis of other components of the induction mechanism, and partly through some other mechanism which is dependent directly or indirectly upon biotin but which is apparently independent of the synthesis of RNA and total protein. Evidence for a direct role for biotin in OCT synthesis is at present only circumstantial. Nevertheless, it is worth noting that Seaman (1958) has reported that biotin is specifically required for the incorporation of glutamate into isolated kinetosomes from Tetrahymena pyriformis. It is possible that biotin may have a similar role in OCT synthesis in yeast. 
The authors wish to thank Hoffmann-La Roche of Nutley, New Jersey, U.S.A., for gifts of norbiotin, homobiotin and biotinol, and Dr K. Hofmann of the Biochemistry Department, University of Pittsburgh, Pennsylvania, U.S.A., for oxybiotin. We are also greatly indebted to Miss Judith Hall for valuable technical assistance. One of us (B. D.) is grateful to the Luccock Research Fund for financial assistance.

\section{REFERENCES}

Abelson, P. H. \& Vogel, H. J. (1955). Amino acid biosynthesis in Torulopsis utilis and Neurospora crassa. J. biol. Chem. 213, 355.

Ables, P. G., Ravel, J. M. \& Shive, W. (1961). The indirect role of biotin in the synthesis of the malic enzyme. J. biol. Chem. 236, 3263.

AHMad, F. \& Rose, A. H. (1962a). Effect of biotin-sparing substances on growth of biotindeficient Saccharomyces cerevisiae and on the synthesis of nucleic acids and protein. J. gen. Microbiol. 28, 147.

Ahmad, F. \& Rose, A. H. (1962b). The role of biotin in the regulation of enzyme synthesis in yeast. Archs. Biochem. 97, 302.

Ahmad, F., Rose, A. H. \& Garg, N. K. (1961). Effect of biotin deficiency on the synthesis of nucleic acids and protein by Saccharomyces cerevisiae. J. gen. Microbiol. $24,69$.

Archibald, R. M. (1944). Determination of citrulline and allantoin and demonstration of citrulline in blood plasma. J. biol. Chem. 156, 121.

Bechet, J., Wiame, J-M. \& De Deken-Grenson, M. (1962). Régulation de la synthèse de l'ornithine transcarbamylase chez Saccharomyces cerevisiae. Archs. int. Physiol. 70, 1.

Blanchard, M. L., Korkes, S., Del Campillo, A. \& Ochoa, S. (1950). Function of biotin in the metabolism of Lactobacillus arabinosus. J. biol. Chem. 187, 875.

Chantrenne, H. (1963). Information in biology. Nature, Lond. 197, 27.

Chinard, F. P. (1952). Photometric estimation of proline and ornithine. J. biol. Chem. 199, 91.

Dixon, B. \& Rose, A. H. (1963). Effect of biotin deficiency on feedback mechanisms controlling the synthesis of ornithine carbamoyltransferase by Saccharomyces cerevisiae. J. gen. Microbiol. 31, vii.

Duerre, J. A. \& Lichstein, H. C. (1961). Malic enzyme induction by lactic acid bacteria. II. Purine and pyrimidine requirements. Can. J. Microbiol. 7, 217.

Estes, J. M., Ravel, J. M. \& Shrve, W. (1956). A role of biotin in the interaction of ornithine and carbamyl phosphate. J. Am. chem. Soc. 78, 6410.

Goldberg, M. W., Sternbach, L. H., Kaiser, S., Heineman, S. D., Scheiner, J. \& Rubin, S. H. (1947). Antibiotin effect of some biotin homologs. Archs. Biochem. 14, 480.

Gorin, L. (1960). Antagonism between substrate and repressor in controlling the formation of a biosynthetic enzyme. Proc. nat. Acad. Sci., Wash. 46, 682.

Hagen, P-O. \& Rose, A. H. (1962). Studies on the biochemical basis of the low maximum temperature in a psychrophilic cryptococcus. J. gen. Microbiol. 27, 89.

Hofmany, K., O'Leary, W. M., Yoho, C. W. \& LiU, T. H. (1959). Further observations on the lipide stimulation of bacterial growth. J. biol. Chem. 234, 1672.

$\mathrm{J}_{\mathrm{ACOB}}$, F. \& MONOD, J. (1961). Genetic regulatory mechanisms in the synthesis of proteins. J. molec. Biol. 3, 318.

Lowry, O. H., Rosebrough, N. J., Farr, A. L. \& Randall, R. J. (1951). Protein measurement with the Folin reagent. J. biol. Chem. 193, 265.

Lynen, F., Knappe, J., Lorch, E., Jütting, G. \& Ringelmann, E. (1959). Die biochemische Funktion des Biotins. Angero. Chem. 71, 481.

MARKhAM, R. (1942). A steam distillation apparatus suitable for micro-Kjeldahl analysis. Biochem. J. 36, 790 .

MrckLe, H. (1948). Tissue disintegrator. J. R. micr. Soc. 68 (Series III), 10.

Miller, L. \& Hougrton, J. A. (1945). The micro-Kjeldahl determination of the nitrogen content of amino acids and proteins. J. biol. Chem. 159, 373. 
Ochoa, S. \& Kaziro, Y. (1961). Biotin enzymes. Fed. Proc. 20, 982.

Plaut, G. W. E. (1961). The influence of biotin nutrition on carbon dioxide fixation and malic enzyme formation by Lactobacillus arabinosus. J. biol. Chem. 236, 61 .

Ravel, J. M., Grona, M. L., Humphreys, J. S. \& Shive, W. (1959). Properties and biotin content of purified preparations of the ornithine-citrulline enzyme of Streptococcus lactis. J. biol. Chem. 234, 1452.

Ravel, J. M., Mollenhauer, B. F. \& Shive, W. (1961). An indirect role of biotin in the synthesis of ornithine transcarbamylase. J. biol. Chem. 236, 2268.

Rogers, P. \& Novelil, G. D. (1960). Cell-free synthesis of ornithine transcarbamylase. Biochim. biophys. Acta, 44, 298.

Rose, A. H. (1960). Excretion of nicotinic acid by biotin-deficient Saccharomyces cerevisiae. J. gen. Microbiol. 23, 143.

Rose, A. H. (1963). On the osmotic behaviour of Saccharomyces cerevisiae as affected by biotin deficiency. J. gen. Microbiol. 31, 151.

Rose, A. H. \& Nickerson, W. J. (1956). Secretion of nicotinic acid by biotin-dependent yeasts. J. Bact. 72, 324.

Rosenberg, H., Ennor, A. H. \& Morrison, J. F. (1956). The estimation of arginine. Biochem. J. 63, 153.

Scher, W. I. \& Vogel, H. J. (1957). Occurrence of ornithine $\delta$-transaminase ; a dichotomy. Proc. nat. Acad. Sci., Wash. 43, 796.

Seaman, G. (1958). Glutamate incorporation into kinetosomes of Tetrahymena pyriformis. Proc. int. Congr. Biochem. p. 142.

Smrth, A. M. \& Agrza, A. H. (1951). The determination of amino acids colorimetrically by the ninhydrin reaction. Analyst, Lond. 76, 623.

WAKIL, S. J. (1961). Mechanism of fatty acid synthesis. J. lipid Res. 2 , 1.

Williams, V. R. \& Fieger, E. A. (1946). Oleic acid as a growth stimulant for Lactobacillus casei. J. biol. Chem. 166, 335. 